\title{
Mean winds at the cloud top of Venus obtained from two-wavelength UV imaging by Akatsuki
}

\author{
Takeshi Horinouchi ${ }^{1,2^{*}} \mathbb{0}$, Toru Kouyama ${ }^{3}$, Yeon Joo Lee ${ }^{2,6}$, Shin-ya Murakami ${ }^{2}$, Kazunori Ogohara ${ }^{4}$, \\ Masahiro Takagi ${ }^{5}$, Takeshi Imamura ${ }^{6}$, Kensuke Nakajima7 ${ }^{7}$ Javier Peralta ${ }^{2}$, Atsushi Yamazaki ${ }^{2}$, Manabu Yamada ${ }^{8}$ \\ and Shigeto Watanabe ${ }^{9}$
}

\begin{abstract}
Venus is covered with thick clouds. Ultraviolet (UV) images at 0.3-0.4 microns show detailed cloud features at the cloud-top level at about $70 \mathrm{~km}$, which are created by an unknown UV-absorbing substance. Images acquired in this wavelength range have traditionally been used to measure winds at the cloud top. In this study, we report low-latitude winds obtained from the images taken by the UV imager, UVI, onboard the Akatsuki orbiter from December 2015 to March 2017. UVI provides images with two filters centered at 365 and $283 \mathrm{~nm}$. While the $365-\mathrm{nm}$ images enable continuation of traditional Venus observations, the 283-nm images visualize cloud features at an $\mathrm{SO}_{2}$ absorption band, which is novel. We used a sophisticated automated cloud-tracking method and thorough quality control to estimate winds with high precision. Horizontal winds obtained from the 283-nm images are generally similar to those from the 365-nm images, but in many cases, westward winds from the former are faster than the latter by a few $\mathrm{m} / \mathrm{s}$. From previous studies, one can argue that the 283-nm images likely reflect cloud features at higher altitude than the 365-nm images. If this is the case, the superrotation of the Venusian atmosphere generally increases with height at the cloudtop level, where it has been thought to roughly peak. The mean winds obtained from the $365-\mathrm{nm}$ images exhibit local time dependence consistent with known tidal features. Mean zonal winds exhibit asymmetry with respect to the equator in the latter half of the analysis period, significantly at $365 \mathrm{~nm}$ and weakly at $283 \mathrm{~nm}$. This contrast indicates that the relative altitude may vary with time and latitude, and so are the observed altitudes. In contrast, mean meridional winds do not exhibit much long-term variability. A previous study suggested that the geographic distribution of temporal mean zonal winds obtained from UV images from the Venus Express orbiter during 2006-2012 can be interpreted as forced by topographically induced stationary gravity waves. However, the geographic distribution of temporal mean zonal winds we obtained is not consistent with that distribution, which suggests that the distribution may not be persistent.
\end{abstract}

Keywords: Venus, Planetary atmosphere, Planetary climatology, Cloud tracking, Image velocimetry, Superrotation, Aerosol, Wind shear, Cloud motion vector, $\mathrm{SO} 2$

\section{Introduction}

Venus is covered with thick clouds that extend from $\sim 45$ to $\sim 70 \mathrm{~km}$ altitude above the mean surface. Ultraviolet (UV) images at around $0.3-0.4 \mu \mathrm{m}$ of the dayside

\footnotetext{
${ }^{*}$ Correspondence: horinout@ees.hokudai.ac.jp

1 Faculty of Environmental Earth Science, Hokkaido University, N10W5, Sapporo, Hokkaido 060-0810, Japan

Full list of author information is available at the end of the article
}

of Venus exhibit remarkable contrast because of a UVabsorbing substance that has not been identified (Pollack et al. 1980; Esposito et al. 1997; Molaverdikhani et al. 2012; Markiewicz et al. 2014). Small-scale features at the cloud top captured by UV images have been used extensively for cloud tracking (e.g., Limaye and Suomi 1981; Limaye et al. 1982, 1988; Rossow et al. 1990; Toigo et al. 1994; Peralta et al. 2007, 2017; Moissl et al. 2009; 
Sánchez-Lavega et al. 2008; Kouyama et al. 2012, 2013; Khatuntsev et al. 2013; Hueso et al. 2015; Patsaeva et al. 2015). These studies are based on planetary exploration by Mariner 10, Pioneer Venus Orbiter (PVO), Galileo, Venus Express (VEx), and Messenger, and have revealed the meridional structure of the superrotation, significant motion associated with the thermal tide, long-term variability of mean winds, and the existence and the variability of planetary-scale waves (Kelvin and Rossby waves). Because of the long-term variability in mean winds and wave activity (Rossow et al. 1990; Khatuntsev et al. 2013; Kouyama et al. 2013), extending available datasets with new observations is of great interest.

The Akatsuki spacecraft was launched in 2010, and 5 years after the failure of orbital insertion in the same year, it was maneuvered to start orbiting Venus on December 7, 2015 (Nakamura et al. 2016). Its present orbital period is about 11 days, and its low orbital inclination $\left(<10^{\circ}\right)$ makes it suitable to observe low latitudes. Akatsuki is equipped with cameras to observe Venus at multiple wavelengths. In this study, we used data from one of these cameras, the Ultraviolet Imager, UVI. UVI images Venus with two filters centered at 365 and $283 \mathrm{~nm}$ (Yamazaki et al. 2017). With the 365-nm filter, UVI provides images equivalent to those from the previous missions listed above; in other words, it provides cloud images contrasted by the unknown UV absorber. The 283-nm filter is designed to match an $\mathrm{SO}_{2}$ absorption band.

Before Akatsuki, spacecraft observations of Venus at $\mathrm{SO}_{2}$ absorption bands were conducted by PVO, which has a spectrometer that covers two broad $\mathrm{SO}_{2}$ absorption bands around 210 and $280 \mathrm{~nm}$, and the VIRTIS-M instrument onboard VEx. To the authors' knowledge, Limaye (1984), who used PVO data, reported the only study that utilized an $\mathrm{SO}_{2}$ absorption band for cloud tracking, based on polarization features, not intensity contrasts as in the above-mentioned studies. Among the four wavelengths he used $(270,365,550$, and $935 \mathrm{~nm})$, the $270-\mathrm{nm}$ polarization features suggested the highest westward wind speed. However, his result at $365 \mathrm{~nm}$ was much slower than the intensity-based results at this wavelength, which suggests that his results may have large errors. Therefore, exploring wavelength dependence using data from Akatsuki is of interest. The VIRTS-M images at $\mathrm{SO}_{2}$ absorption bands are potentially useful for cloud tracking, but that has not been conducted.

The purpose of this study is to report the initial results of cloud tracking using UVI images. After introducing a case study to show the overall performance at both wavelengths, we focus on mean winds and the similarities and differences of winds obtained at the two wavelengths based on data acquired over a year and 4 months. In this study, we limit our scope between $50^{\circ} \mathrm{S}$ and $50^{\circ} \mathrm{N}$, and we mainly focus on low latitudes. Cloud tracking with UVI is more difficult for high latitudes because of Akatsuki's equatorial orbit and because UV cloud features at midto-high latitudes are exhibited as featureless streaks (Rossow et al. 1980, Titov et al. 2012). Therefore, the study of flow at high latitudes is left for future study.

\section{Data and methods}

We used the version 20170601 Level-3 UVI data covering the period from December 7, 2015, to March 25, 2017, in which 3231 images are available. The level-3 data consist of radiance mapped onto a longitude-latitude grid with a resolution of $0.125^{\circ}$ in both longitude and latitude, as described by Ogohara et al. (2017). Akatsuki observes Venus from orbits with low inclination $\left(<10^{\circ}\right)$, and its orbital period is about 10 days (Nakamura et al. 2016). When observed from the apoapsis, the radius of Venus on UVI images is $\sim 80$ pixels, corresponding to a horizontal resolution of $80 \mathrm{~km}$ at the sub-spacecraft point. The UVI images consist of $1024 \times 1024$ pixels. If the imaged radius of Venus is 400 pixels, for example, the sub-spacecraft point resolution is $15 \mathrm{~km}$.

Figure 1 shows examples of radiance at 365 and $283 \mathrm{~nm}$, where the imaged Venus radii are $\sim 190$ pixels. In the Akatsuki Level-3 data, spacecraft navigation data are refined by using a limb-fitting technique (Ogohara et al. 2012). In this study, we did not use images for which the limb fitting was unsuccessful, which occurs when the spacecraft is too close to Venus.

The accuracy of orientation correction is estimated to be better than 0.1 pixels (Ogohara et al. 2017; the simulated error is $\sim 0.04$ pix for UVI). The green dots in Fig. 1 indicate the limbs obtained by fitting where the gradients of radiance are greatest. The fitting results are used to adjust the camera's boresight orientation, and geographic mapping is conducted by assuming that the observed altitude is $70 \mathrm{~km}$ above the mean surface. The cloud-top altitude is known to vary (e.g., Lee et al. 2012), but the current assumption has little impact on mapping except near the limb. The yellow dots in the figure indicate the mapped limbs, which are supposed to be at $70 \mathrm{~km}$. The mapped limbs in the figure are slightly smaller than the fitted limbs by $\sim 1$ pixel, corresponding to $\sim 30 \mathrm{~km}$; thus, brightness exists outside the mapped limbs. This discrepancy is presumably caused by instrumental point spread (Yamazaki et al. 2017) and the effect of upper haze. The upper haze exists above the cloud top with smoothly decreasing vertical number density up to $\sim 90 \mathrm{~km}$ (Wilquet et al. 2009, 2012; Luginin et al. 2016). Quantitatively, some error still may exist in the calibration of image scales, but we assume that it should be smaller than a couple tens of kilometers in terms of the radius of Venus. 


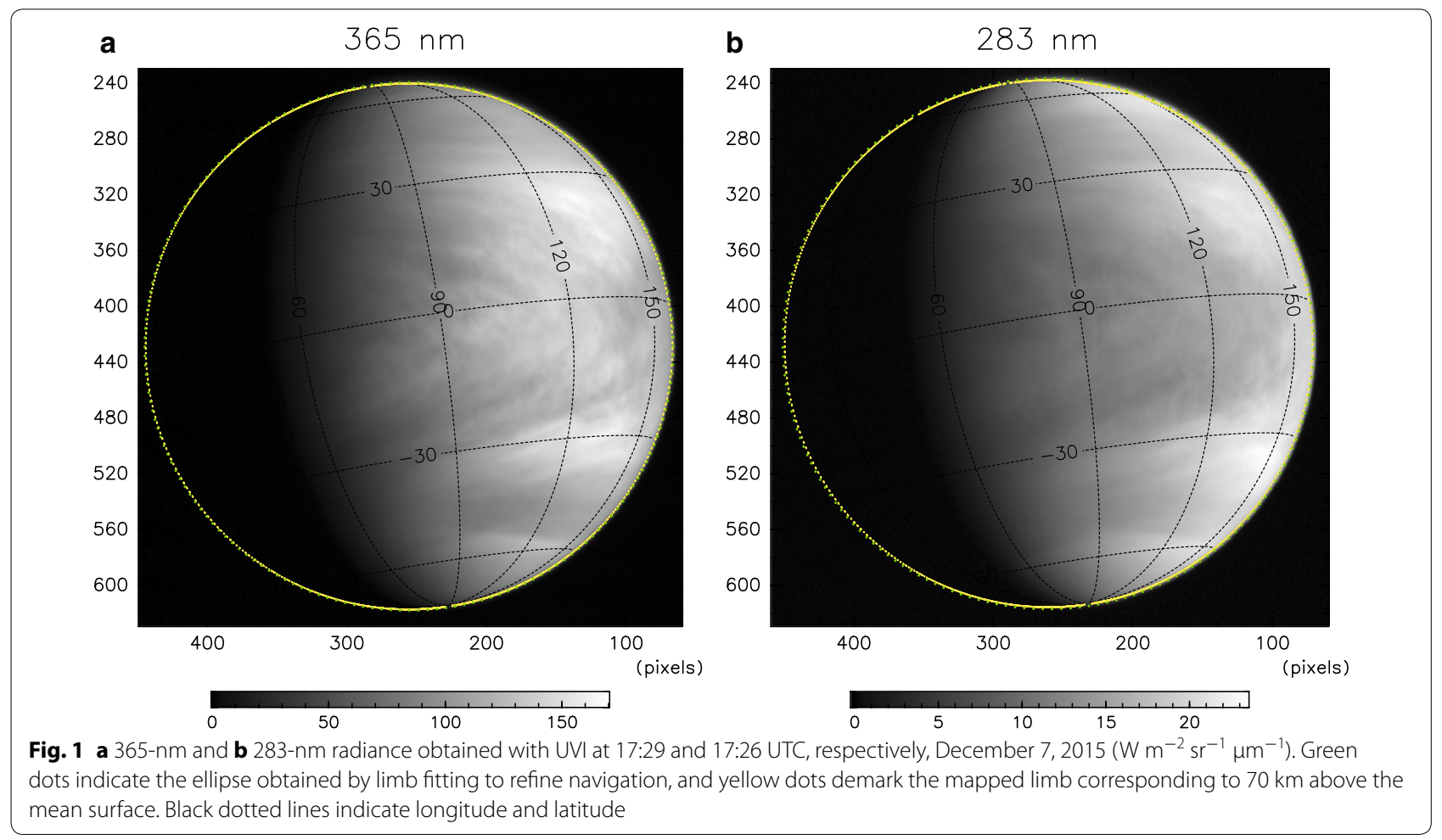

We conducted cloud tracking using a novel automated method proposed by Ikegawa and Horinouchi (2016; hereinafter IH16) and Horinouchi et al. (2017a; hereinafter H17a). This method is based on traditional template matching in which cross-correlation peaks are searched (e.g., Limaye and Suomi 1981; Kouyama et al. 2012), but it can utilize multiple (more than two) images consistently to accurately estimate horizontal winds (IH16). The method also supports a sophisticated error correction with the relaxation labeling technique, which is similar to that used by Kouyama et al. (2012) but is significantly improved (H17a). The parameter setting is the same as that of Horinouchi et al. (2017b): The template size is $7.5^{\circ}$ both in longitude and in latitude; horizontal winds are obtained at grid points with a $3^{\circ}$ interval; and the spatial sliding average of cross-correlation surfaces is employed at adjacent grid points (center plus the four upper/lower/left/right points, called the "STS"-type setting in IH16). See Method section (online supplement) of Horinouchi (2017b) for further details, in addition to the method descriptions of IH16 and H17a. Horizontal wind data obtained by cloud tracking are often called cloud motion vectors (CMVs); therefore, we use this abbreviation below for brevity.

When Akatsuki's geometry of observations is favorable for the dayside of Venus, UVI is operated to conduct a sequence of 283- and 365-nm imaging at a time interval of $\sim 3 \mathrm{~min}$. Normally, this sequence is repeated every $2 \mathrm{~h}$ for several to $16 \mathrm{~h}$; imaging is not continued over a full day because the attitude of the spacecraft must be altered for data transfer to the Earth.

Cloud tracking is conducted for all available twohourly image triplets over $4 \mathrm{~h}$ for each of the two wavelengths. In other words, if the UVI imaging sequence is conducted at $10,12,14, \ldots, 22 \mathrm{~h}$ in a day, we conducted cloud tracking using the images at 10-12-14, 12-14-16, ..., 18-20-22 h, which provides five CMV datasets for each wavelength. However, we used images with slightly longer time intervals on December 7, 2015, as introduced in the next section.

The velocity error associated with the geographic mapping error introduced above is estimated as follows: If the error in the boresight orientation is 0.1 pixels, it corresponds to a deflection of the sub-spacecraft point by $8 \mathrm{~km}$ in the worst case, i.e., when the spacecraft is at the apoapsis. The mapping error worsens at high satellite zenith angles, but we did not use any data where the angle was greater than $70^{\circ}$. An assumed error of $15 \mathrm{~km}$, for example, is equivalent to an error of $1 \mathrm{~m} / \mathrm{s}$ if divided by $4 \mathrm{~h}$. The possible bias in image scaling may result in a larger positioning error near the limb. However, its impact on velocity estimation is limited. For example, a spurious image enlargement of $0.3 \%$ (corresponding to $20 \mathrm{~km}$ in terms of the radius of Venus) leads to the overestimation 
of wind speed by the same ratio at the sub-spacecraft point. In this case, a superrotation of $100 \mathrm{~m} / \mathrm{s}$ will be overestimated by $0.3 \mathrm{~m} / \mathrm{s}$. In total, we can assume that the error associated with incorrect geographic mapping is generally up to $1 \mathrm{~m} / \mathrm{s}$. We ignore this error as it is relatively small in what follows.

The geographic grid we use is generally finer than the original pixel scale, and we further derive sub-pixel displacement; therefore, the image resolution does not quantize the obtained CMVs. However, it does not guarantee high precision, as sub-images used for template matching could be featureless or could be deformed excessively over time. IH16 proposed a measure of precision based on the $90 \%$ confidence bounds of cross-correlation. In this method, the size of the region of cross-correlation surface peaks exceeding the lower confidence bound is measured. Qualitatively, the estimated precision becomes higher when the cross-correlation surface peak is sharper. The precision measures are derived separately for zonal and meridional velocities, which are termed as $\varepsilon_{u}$ and $\varepsilon_{v}$, respectively. Although they are not direct measures of the confidence bounds of velocity, they are found to be somewhat consistent with manual (visual) estimation of the ambiguity of cloud tracking (IH16). Note that the precision improves if the number of images used simultaneously is increased (IH16). However, because we used only three images for each tracking in this study, the expected precision is not much higher than that of traditional two-image tracking. The precision is generally low at middle and high latitudes because of the dominance of streaky features.

Precision does not guarantee accuracy. The greatest source of error in tracking by template matching is erroneous peak matching. In our method, the use of multiple images and the relaxation labeling technique reduce the erroneous match (H17a). However, CMVs that are inconsistent with those at surrounding grid points can still survive. Therefore, we apply screening to satisfy the deformation consistency principle as proposed by $\mathrm{H} 17 \mathrm{a}$ (see their Sect. 5.1).

The actual quality control we employed is as follows: We reject CMVs associated with cross-correlation coefficients smaller than 0.5. In screening based on deformation consistency, the tunable parameter $\alpha$ in $\mathrm{H} 17 \mathrm{a}$ was set to 1 . We further reject the CMVs with a combined precision measure $\varepsilon \equiv \max \left(\varepsilon_{u}, \varepsilon_{v}\right)$ greater than $10 \mathrm{~m} / \mathrm{s}$. In "Mean winds" section, the threshold of $\varepsilon$ is set to $20 \mathrm{~m} / \mathrm{s}$ for initial screening, and further screening based on $\varepsilon$ statistics was conducted as described below. In addition, when computing the mean quantities shown in that section, we excluded CMVs associated with the template regions at which the satellite zenith angles were greater than $60^{\circ}$.
In our analysis period from December 7, 2015, to March 25, 2017 (475 days), UVI acquired images during a total of 295 days. We obtained cloud-tracking results from 1034 365-nm image triplets for 193 days and 1,039 283-nm image triplets for 195 days; observational conditions in the other 100 days were unsuitable for tracking using three two-hourly images.

\section{Case study}

Here we show the results from UVI images obtained on December 7, 2015, which was the first day of Akatsuki's observations. UVI imaging on that day was conducted at $5,17,20$, and $22 \mathrm{~h} \mathrm{UTC;} \mathrm{tracking} \mathrm{was} \mathrm{conducted} \mathrm{with}$ the last three images. Venus's diameter in the images is $\sim 380$ pixels at $17 \mathrm{~h}$ and $\sim 320$ pixels at $22 \mathrm{~h}$, corresponding to resolutions at the sub-spacecraft point of $30-40 \mathrm{~km}$. During this 5 -h period, the subsolar longitude moved eastward by $0.6^{\circ}$ from $143.0^{\circ}$, and the subspacecraft longitude moved westward by $2^{\circ}$ from $82.5^{\circ}$. The obtained wind vectors were screened to retain only those for which the precision measure $\varepsilon$ was smaller than $10 \mathrm{~m} / \mathrm{s}$. Typical $\varepsilon$ values at low latitude are smaller than $4 \mathrm{~m} / \mathrm{s}$, as shown below.

Figure $2 \mathrm{a}$ shows the horizontal winds obtained from the $365-\mathrm{nm}$ images. Because the flow is dominated by superrotation, we show with arrows the deviation from a pure solid-body rotation with westward speed of $100 \mathrm{~m} / \mathrm{s}$ at the equator (i.e., $[u+100 \cos \varphi, v] \mathrm{m} / \mathrm{s}$, where $u$ and $v$ are zonal and meridional velocities, and $\varphi$ is latitude). The movement of hypothetical tracers advected linearly with time by the derived winds (shown by the cross marks in Fig. $2 \mathrm{a}-\mathrm{c}$ ) has a good correspondence with the movement of small-scale ( several hundreds of kilometers) radiance features, which suggests that our results are appropriate. The radiance was band-pass-filtered by applying Gaussian filters with half-widths at half-maxima of $4^{\circ}$ (high-pass) and $0.3^{\circ}$ (low-pass) for both longitude and latitude.

The flow field shown in Fig. 2a exhibits zonal and meridional divergence consistent with the tidal features at the cloud-top level shown by previous studies (e.g., Limaye 1988; Del Genio and Rossow 1990; Khatuntsev et al. 2013; Patsaeva et al. 2015). This snapshot-flow field is much smoother than those reported in earlier studies (e.g., Limaye and Suomi 1981; Kouyama et al. 2012), except IH16. The present paper is likely the first report to show tidal features in a snapshot. The smoothness is partly because of the overlap of the template regions (while the template regions size is $7.5^{\circ}, \mathrm{CMV}$ grid points are taken at a $3^{\circ}$ intervals, and a sliding average is applied to cross-correlation surfaces), but note that no smoothing was applied to the derived winds. 


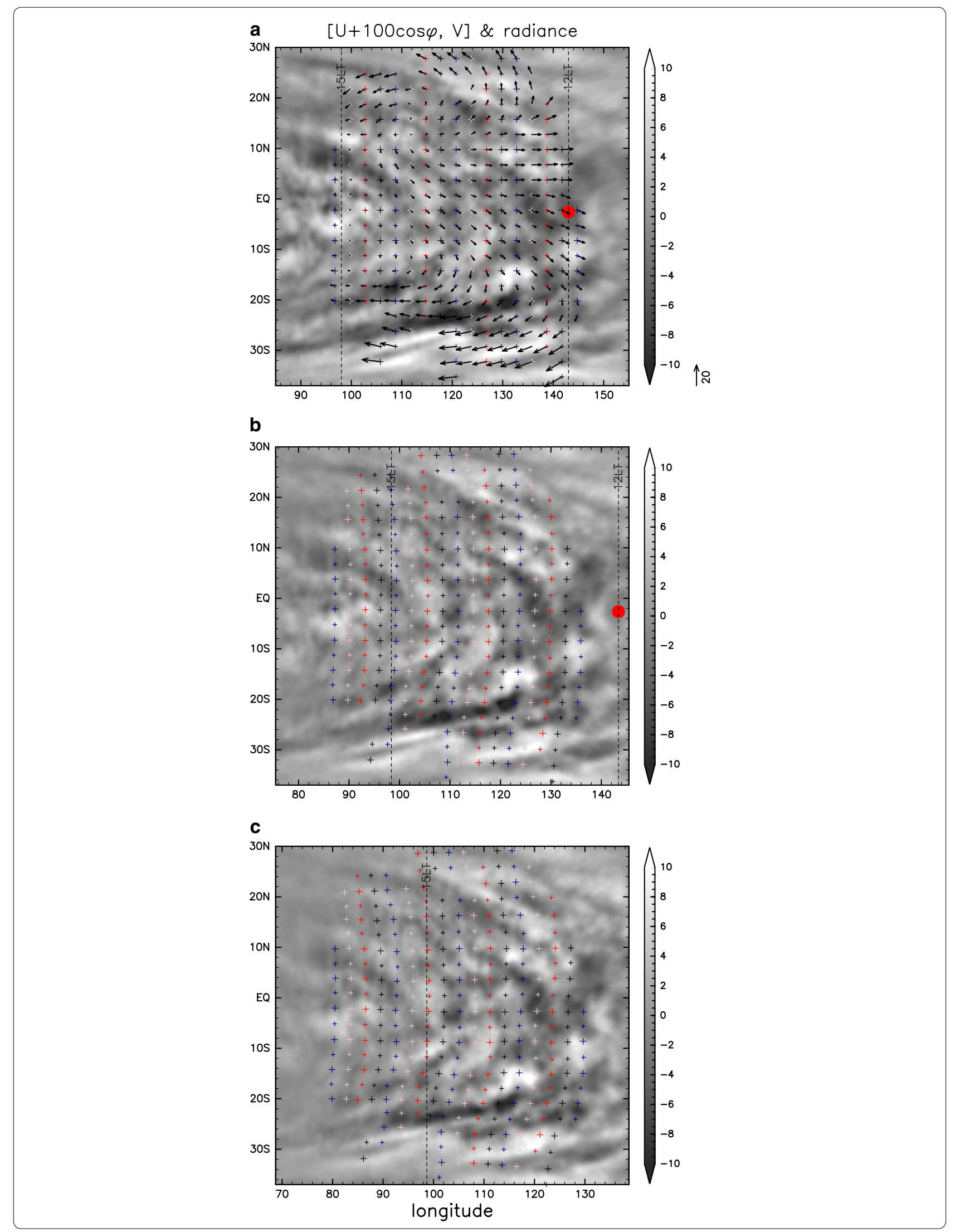


(See figure on previous page.)

Fig. 2 Band-pass filtered 365-nm radiance and cloud-tracking results for December 7, 2015; a 17:29, b 20:19, and c 22:19 UTC used for tracking $\left(\mathrm{W} \mathrm{m} \mathrm{m}^{-2} \mathrm{sr}^{-1} \mu \mathrm{m}^{-1}\right)$. Arrows a show the horizontal wind deviation from a pure solid-body rotation with a westward speed of $100 \mathrm{~m} / \mathrm{s}$ at the equator. The arrow on the lower right of the panel indicates the length scale of $20 \mathrm{~m} / \mathrm{s}$. The longitude (abscissa) ranges of the panels are shifted to cancel the solid-body rotation. Colored " + " symbols at the initial time $\mathbf{a}$ show the centers of the template regions for cloud tracking, whereas those at later times b, c show their positions advected linearly with time by the CMVs. Red bullets indicate the subsolar point. Vertical dotted lines indicate where the local time is 12 and $15 \mathrm{~h}$

We next show the results obtained from the images at 283-nm. Except for that of Limaye (1984), this is the first report of cloud tracking using images at $\mathrm{SO}_{2}$ absorption bands (see "Introduction" section). Figure 3 shows the result from the 283-nm images taken almost simultaneously with the 365-nm images shown in Fig. 2. Smallscale features are similar between the two wavelengths. The cross-correlation between the band-passed radiances at the two wavelengths is 0.73 , if the results from the three image pairs shown in these figures $(17,20$, and $22 \mathrm{~h})$ are averaged. Its square value $\left(0.73^{2}=0.53\right)$ indicates that half of the variance at this scale is common between the two wavelengths.

As expected from the correlation, the wind estimates at the two wavelengths shown in Figs. 2 and 3 generally agree well with each other, but 283-nm winds often exhibit faster westward speeds. Figure 4 shows closeup images for close inspection. Winds from the two filters agree better with each other in the eastern half $\left(120-145^{\circ} \mathrm{E}\right.$ in the first image) than in the western half $\left(95-120^{\circ} \mathrm{E}\right.$ in the first image) of the region shown in the figure. The radiance features agree well between the two filters in the eastern region. In the western region, agreement of features between the two filters is weaker. Furthermore, although we can roughly follow the movement of features at the velocities derived for each filter, traceability is not good everywhere, and it appears that the temporal change of radiance features is not always characterized by simple advection. This regional contrast is captured in the precision parameter $\varepsilon$; its value is $2-4 \mathrm{~m} / \mathrm{s}$ at $365 \mathrm{~nm}$ and $2-6 \mathrm{~m} / \mathrm{s}$ at $283 \mathrm{~nm}$ in the eastern region, whereas it is $3-7 \mathrm{~m} / \mathrm{s}$ at $365 \mathrm{~nm}$ and $4-10 \mathrm{~m} / \mathrm{s}$ at $283 \mathrm{~nm}$ in the western region (not shown), reflecting the greater ambiguity in the western region. The zonal wind differences between the two wavelengths are $<2 \mathrm{~m} / \mathrm{s}$ in the eastern region (except around its western end), whereas these differences are 4-12 m/s in the western region (not shown). Therefore, the disagreement of winds in the western region appears marginally significant; here, we cannot assert statistical significance, because $\varepsilon$ is not a direct measure of the confidence bounds of velocity (see "Data and methods" section). Inspection of many UVI images sometimes suggests hints of multiple superposed velocities (not shown). This aspect will be investigated further in a future study.

Figure 5 summarizes the wind estimates for December 7,2015 . Note that the precision estimates (stippled where $\varepsilon_{u}$ or $\varepsilon_{v}$ is smaller than $4 \mathrm{~m} / \mathrm{s}$ ) tend to be better (i.e., smaller) in the eastern half of the region shown in Fig. 4. The stippled area in Fig. 5c is smaller than that in Fig. 5a, which is consistent with the fact that $283-\mathrm{nm}$ images are noisier than 365-nm images.

\section{Overall differences between 283- and 365-nm results}

Figure 6 shows the differences between the winds obtained at the two wavelengths (283-nm results minus $365-\mathrm{nm}$ results) averaged over the observation period. These differences were computed by selecting simultaneous tracking results at two wavelengths, finding grid points where the CMVs passed the screening at both wavelengths, and averaging their differences over longitude and time. The results suggest that the westward winds obtained from 283-nm images are faster than those from 365-nm images, on average; the mean difference is $2-4 \mathrm{~m} / \mathrm{s}$. In total, $77 \%$ of the differences used to make Fig. 6a are negative. The differences in meridional winds are small and anti-symmetric with respect to the equator, indicating that poleward flow is faster at $283 \mathrm{~nm}$.

\section{Mean winds and long-term variability}

Here we show analyses of the winds obtained from the entire period (December 2015 to March 2017). All the quantities shown in this section are derived from the daily mean values determined as follows. (Here, the daily mean is based on the Earth's calendar day.) Observation time for consecutive UVI imaging is typically over half a day, but it varies significantly day by day. Therefore, to avoid uneven weighting depending on the observation hours, zonal and meridional winds are first averaged for each day (based on UTC) at each geographic (longitudelatitude) grid point. For the precision measures $\varepsilon_{u}$ and $\varepsilon_{v}$, the daily values are defined as $\bar{\varepsilon}_{x} \equiv \sqrt{\sum_{i=1}^{n} \varepsilon_{x}^{2}} / n$ instead of averaging, where $x$ represents $u$ or $v$, and $n$ is the number of the valid data for each day at each grid point; here, valid data indicate those that passed the screening stated in "Data and Methods" section. The above definition of $\bar{\varepsilon}_{x}$ 

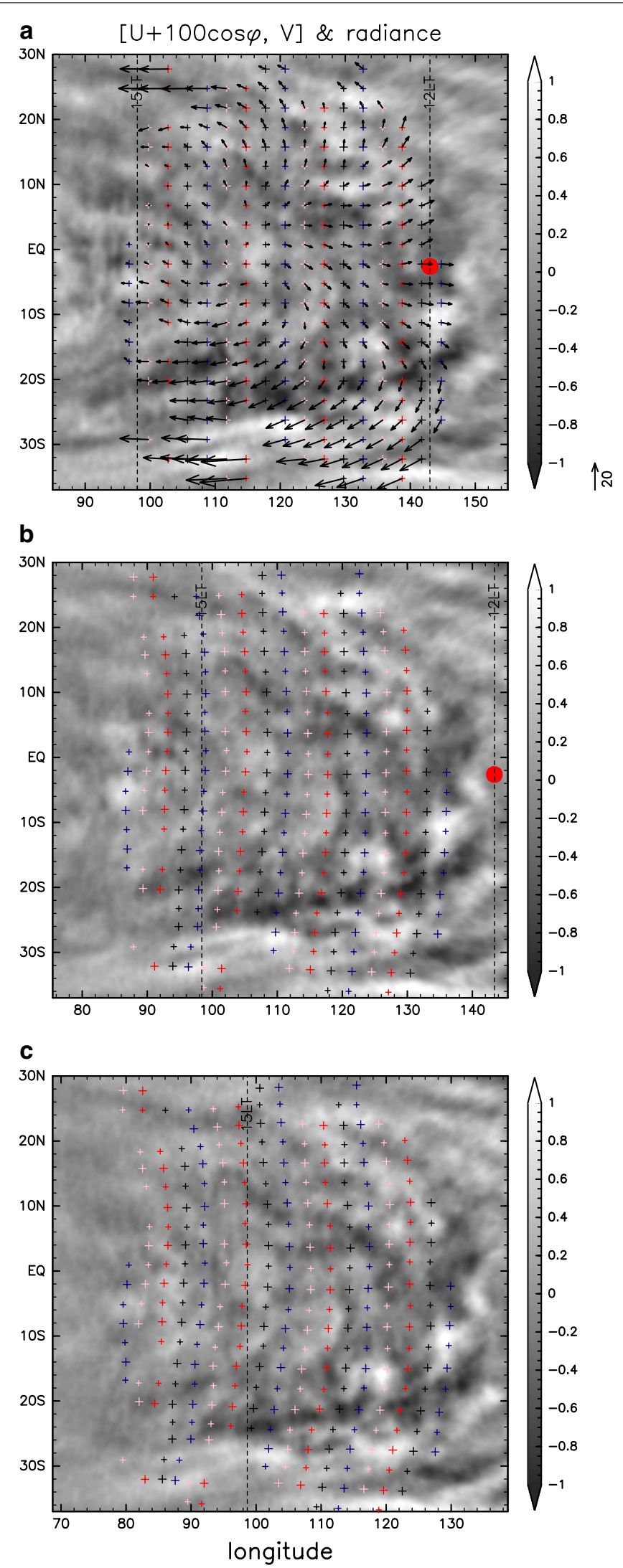

Fig. 3 As in Fig. 2 but for the high-passed radiance and winds from 283-nm observations at a 17:26, b 20:16, and c 22:16 UTC 


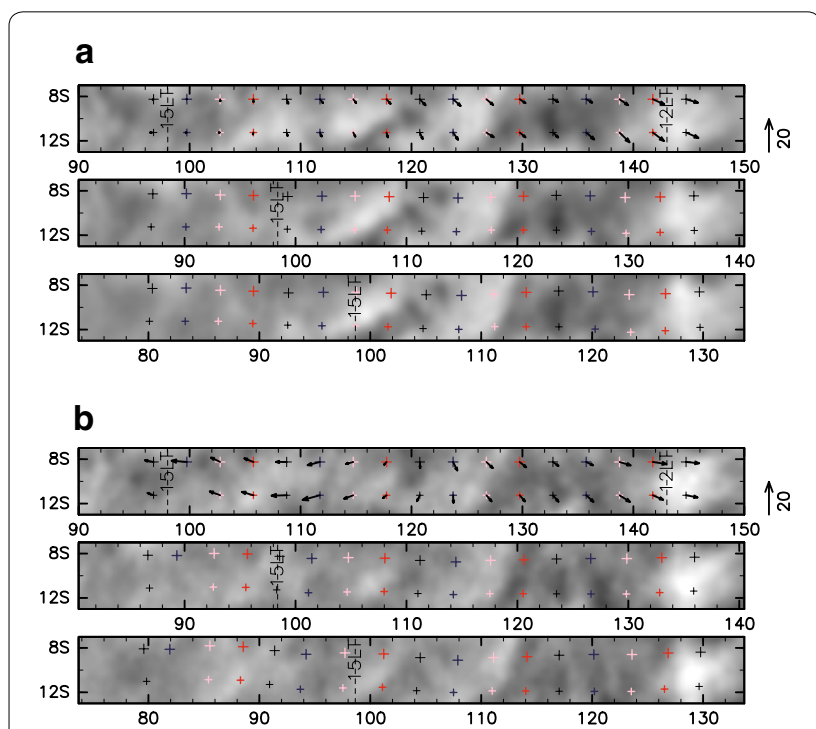

Fig. 4 Same as a Fig. $2 a-c(365 \mathrm{~nm})$ and b Fig. $3 a-c(283 \mathrm{~nm})$, but the latitudinal range is limited to $13^{\circ} \mathrm{S}-7^{\circ} \mathrm{S}$ for close inspection

is suitable to treat random errors. Where the long-term mean is used, the data are further summed as

$$
\left\langle\varepsilon_{x}\right\rangle \equiv \sqrt{\sum_{i=1}^{N} \bar{\varepsilon}_{x}^{2} / N} \quad(x \text { represents } u \text { or } v)
$$

where $N$ is the number of daily values used to compute the long-term mean at each grid point (whether on longitude-latitude or local time-latitude grid).

The long-term mean zonal and meridional winds are shown with respect to local time and longitude in Fig. 7. Here, the local time is based on the initial image of the 4-hourly tracking, but it is increased by $30 \mathrm{~min}$, which corresponds to a westward shift of $7.5^{\circ}$. This treatment is performed to roughly take westward movement into account. (A 2-h zonal movement at $100 \mathrm{~m} / \mathrm{s}$ displaces longitude by $6.7^{\circ}$ at the equator.) The $365-\mathrm{nm}$ results (Fig. 7a, b) are consistent with previous studies (e.g., Limaye 1988; Del Genio and Rossow 1990; Moissl 2009; Khatuntsev et al. 2013; Hueso et al. 2015). In particular, dayside zonal wind at low latitude is slowest around the longitude corresponding to the local noon, and meridional wind divergence is strongest in the early to midafternoon. Quantitatively, it appears that our results obtained at $365 \mathrm{~nm}$ are closer to those obtained from PVO (Limaye 1988; Del Genio and Rossow 1990) and VEx/VIRTIS (Hueso et al. 2015) than those from VEx/ VMC (Moissl 2009; Khatuntsev et al. 2013); for instance, the westward wind minimum is located slightly to the morning side of the longitude of local noon. However, it should be noted that the tidal structure may be subject to long-term variability and that its statistics may be affected by the partial sampling that arises from the use of a single satellite, as explained in what follows.

The values obtained for $\varepsilon_{u}$ and $\varepsilon_{v}$ are rather small at low latitudes, which indicate good precision; stipples in Fig. 7 show where their values are smaller than $4 \mathrm{~m} / \mathrm{s}$. However, it should be noted that they do not include any effects of biases that arise from limited sampling and natural variability. As a measure of low-frequency variability, Fig. 7 shows the standard deviation at each latitude-local time grid, which is computed after averaging over time with 10-day bins. This binning is conducted to remove the shortterm variability associated with planetary-scale waves (e.g., Kouyama, et al. 2012), although it is imperfect because the bins may be sparsely filled. The low-frequency variability as measured by this standard deviation at low latitude is predominantly $4-8 \mathrm{~m} / \mathrm{s}$ for zonal wind (light gray hatching) and smaller than $4 \mathrm{~m} / \mathrm{s}$ for meridional wind (gray hatching).

Figure 8 presents the evolution of mean zonal winds over time. In particular, Fig. $8 \mathrm{a}$ and b shows 5 -day mean zonal winds between $20^{\circ} \mathrm{S}$ and $20^{\circ} \mathrm{N}$ in terms of local time and observational time. The near-noon maxima (minima in terms of wind speed) stated above and shown in Fig. 7 can be seen at most times with both wavelengths. Figure 8 shows that the difference in wind estimates between the two wavelengths (i.e., 283-nm estimated winds are faster than $365-\mathrm{nm}$ estimated winds) is persistent. In addition, long-term variability is apparent over timescales of $\mathrm{O}(100)$ days, which appears to be consistent with variability with a period $\sim 250$ days suggested by Kouyama et al. (2013) from VEx/VMC data. The long-term variability is fainter in meridional wind (not shown), which is consistent with the fact that the standard deviations shown in Fig. $7 \mathrm{~b}$ and $\mathrm{d}$ (for meridional winds) are generally smaller than those in Fig. 7a and c (for zonal winds).

Figure $8 \mathrm{a}, \mathrm{b}$ suggests that the long-term variability can be reflected in local time dependence (as shown in Fig. 7) to some extent through the slowly moving observational local time window. Note that the observational window is associated with the spacecraft's orbit; although Akatsuki takes a low-inclination orbit, images suitable for cloud tracking are obtained mainly for the hemisphere around the apoapsis longitude because the orbit is highly elliptic (Nakamura et al. 2016). The apoapsis longitude moves as Venus rotates with a period of 243 days. Similar observational windows exist for the past orbiters as well.

Figures 9 and 10 show the local time-observational time plots of 5-day mean zonal winds as in Fig. 8 but for $20-35^{\circ} \mathrm{S}$ and $20-35^{\circ} \mathrm{N}$, respectively. These figures suggest a $\mathrm{O}(100)$-day variability similar to that observed at low latitude (Fig. 8) within each of the two observational periods separated at September 2016. In addition, there is notable hemispheric difference in zonal winds observed at $365 \mathrm{~nm}$ in the latter period. 


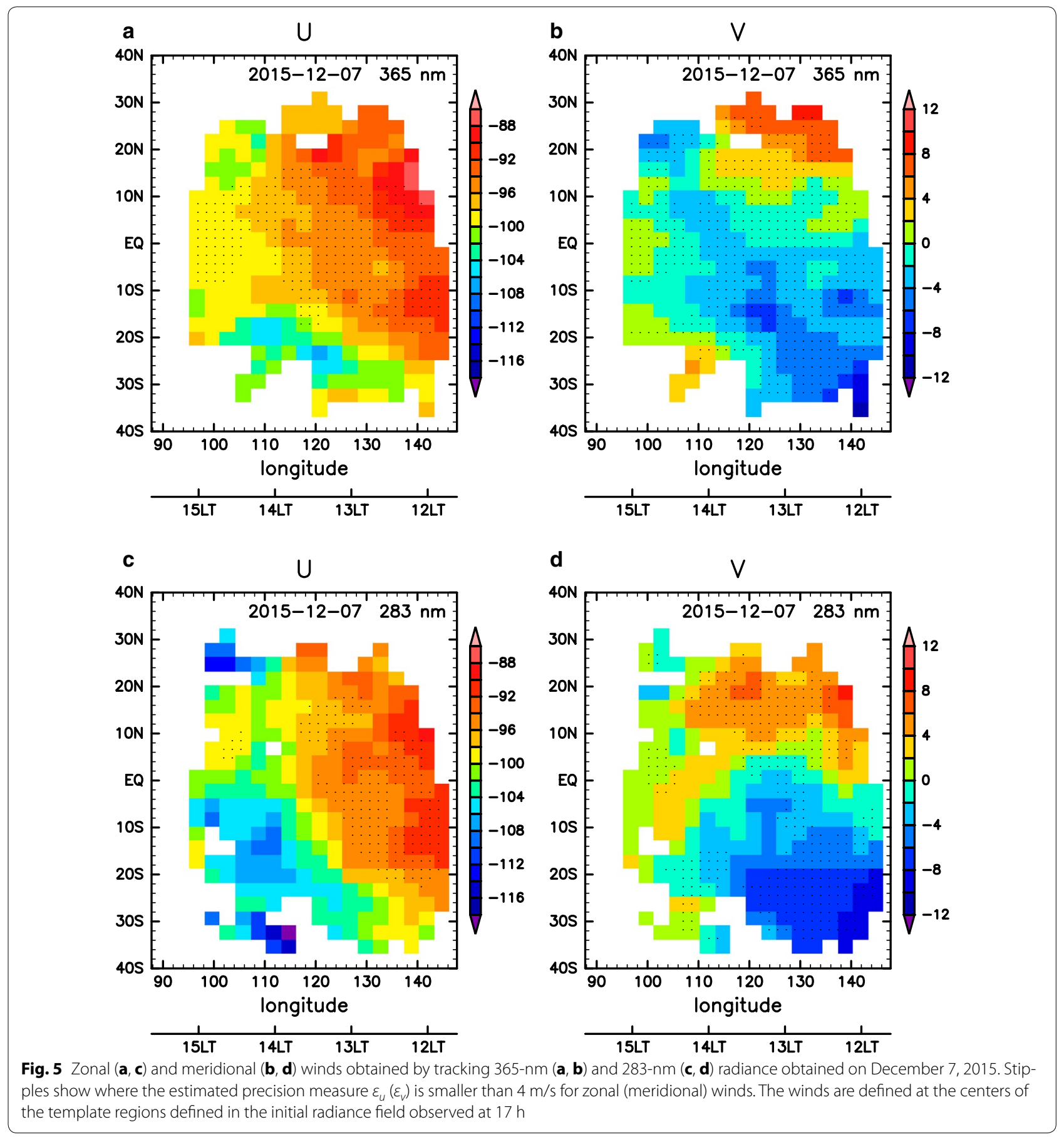

Local time statistics for the two periods are presented in Figs. 11 and 12. The 365-nm zonal winds are roughly symmetric about the equator before September 2016 (Fig. 11a). However, they are significantly asymmetric after that (Fig. 11c), and zonal winds are faster in the southern hemisphere. Interestingly, the 283-nm zonal winds in the same period (Fig. 12c) are more meridionally symmetric.
The mean winds over our analysis period (December 2015-March 2017) obtained from the 365-nm UVI images were compared with the mean winds obtained by manually tracking VEx/VIRTIS images at 365-nm from April 2006 to February 2012 (Hueso et al. 2015). Figure 13 shows the results for the local time range between 11 and $13 \mathrm{~h}$. The mean zonal winds in the present analysis period (black) are slower than those in the earlier 

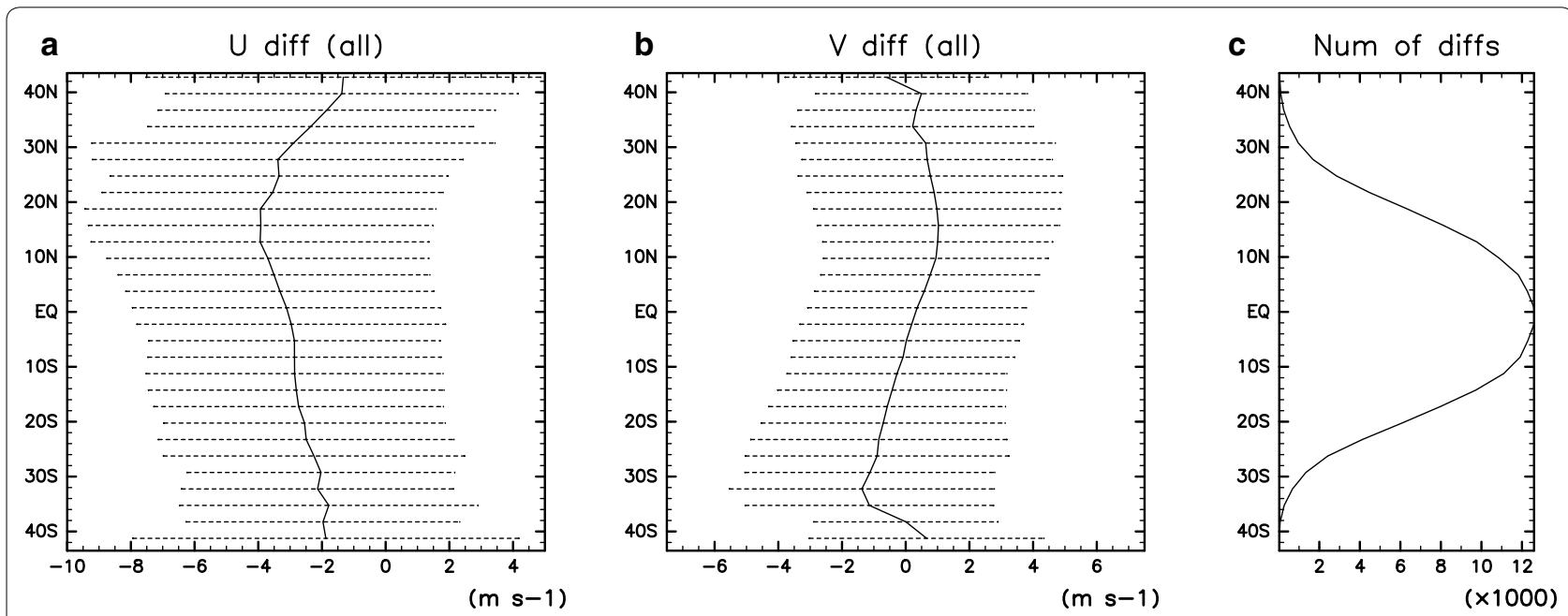

Fig. 6 Mean differences in zonal (a) and meridional $(\mathbf{b})$ winds $(\mathrm{m} / \mathrm{s}$ ) between the two UV filters (283-nm results minus 365-nm results) averaged over the observational period (December 2015-March 2017). c The number of wind differences used to derive the mean at each latitude. See the text for the matching condition. The dashed lines $\mathbf{a}, \mathbf{b}$ show \pm the standard deviation at each latitude

times (red), whereas the mean meridional winds are similar. The standard deviations of zonal winds (dotted lines) are much greater in the VIRTIS results than in the UVI results. The primary reason of this difference is presumably because the latter has longer time coverage; as reported by Khatuntsev et al. (2013), the cloud-top winds exhibit large multi-year variability.

Using data from the VEx/VMC instrument, Bertaux et al. (2016) suggested the existence of longitudinal dependence of mean zonal winds. For comparison, we calculated similar statistics using our results from Akatsuki/UVI. Figure 14a shows the temporal mean zonal wind averaged simply at each longitudinal and latitudinal grid point. The results exhibit considerable longitudinal variation. However, Fig. $8 \mathrm{c}$ shows that the observational time coverage is quite limited for each longitude. Furthermore, there is no clear longitudinally fixed structure that persists over the observational period. Comparison of Fig. 8a and c indicates that local time dependence is more robust. Therefore, we show in Fig. 14b the temporal mean zonal winds in which the local time dependence is subtracted, even though the latter also is not free from biases caused by partial sampling (as mentioned above). This figure was computed as follows: First, local time dependence was determined by subtracting from the local-time dependent mean winds (as shown in Fig. 7) their zonal mean; then, the local time dependence was subtracted from the daily mean zonal winds; finally, the result was averaged over the observational period.
As expected, the mean zonal winds shown in Fig. 14b exhibit smaller longitudinal variation than those in Fig. 14a. However, they are qualitatively similar. The longitudinal dependence we obtained does not agree with that shown by Bertaux et al. (2016), even qualitatively. Specifically, they showed that low-latitudinal westward winds in the eastern hemisphere $\left(0-180^{\circ}\right)$ are slower than those in the western hemisphere, but the hemispheric contrast indicated by Fig. 14b (as well as Fig. 14a) is opposite.

Quantitatively, the geographic variability shown in Fig. 14b is much (several times) smaller than that shown by Bertaux et al. (2016). We do not insist that Fig. 14b represents true geographic dependence. Note that the standard deviations of the 5-day mean zonal winds are relatively large over longitudes between $70^{\circ}$ and $160^{\circ}: 4-8 \mathrm{~m} / \mathrm{s}$, indicated by light gray hatching, or even $8-12 \mathrm{~m} / \mathrm{s}$, indicated by white hatching. Therefore, even though the expected precision of our result is high (as indicated by stipples representing $\varepsilon$ statistics smaller than $4 \mathrm{~m} / \mathrm{s}$ ), the longitudinal variability shown in Fig. 14b may be within the uncertainty attributed to imperfect sampling. However, whether the geographic distribution we obtained is significant or not, it is interesting that the topographic impact suggested by Bertaux et al. (2016) is not apparent all the time.

\section{Discussion}

What causes the difference in zonal winds obtained from the 283- and 365-nm images? A possible explanation is 


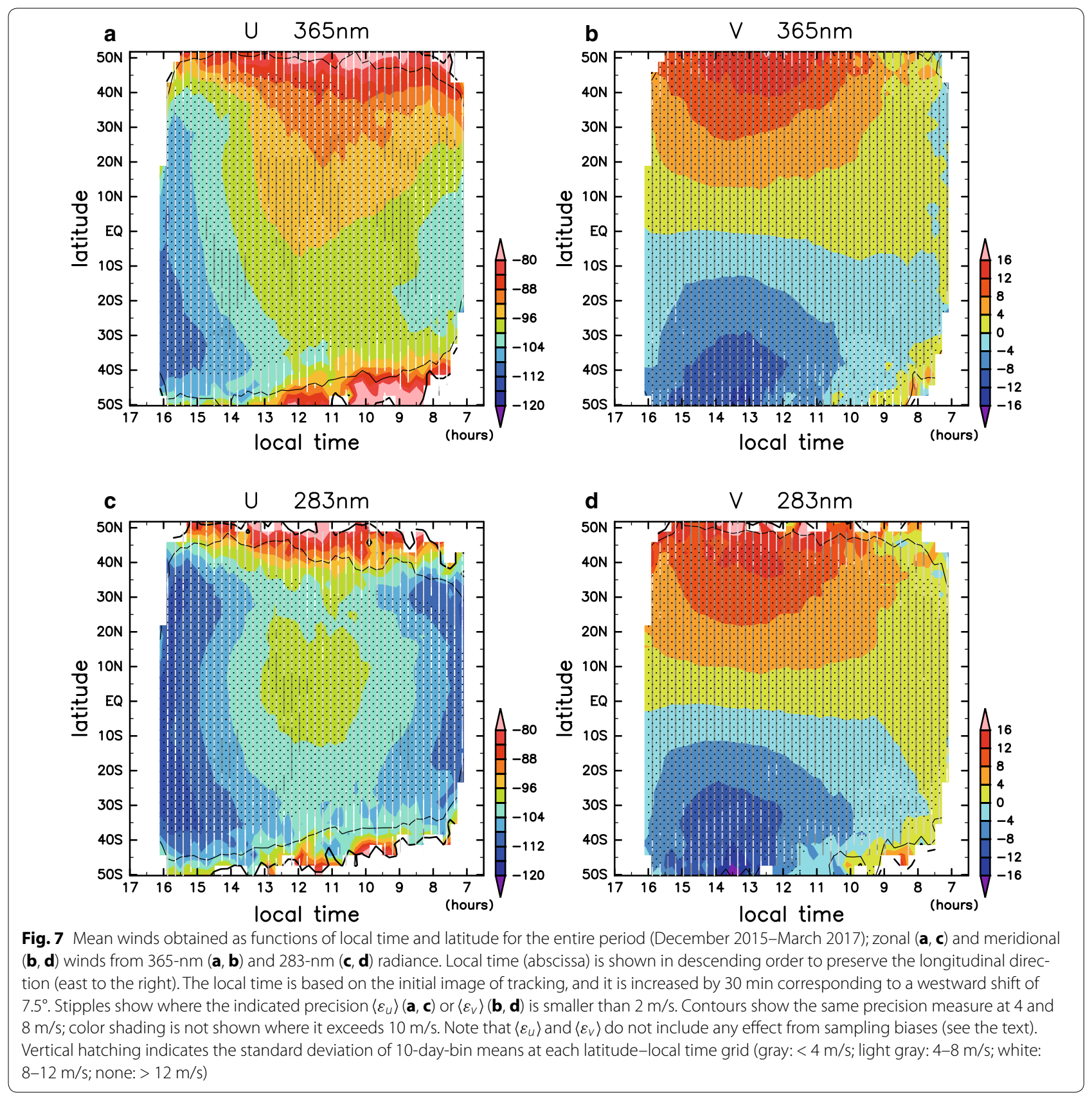

that when the velocities disagree, small-scale features at the two wavelengths reflect clouds at different heights, and that the difference therefore is from vertical shear. Another possibility is that while the velocity captured at one wavelength represents the flow velocity, the velocity captured at the other wavelength represents the phase velocity of atmospheric waves. A close inspection suggests that the latter indeed appears the case sometimes, but in most cases, it appears unlikely. For the spatial scale of our template $\left(7.5^{\circ}\right.$, i.e., about $\left.800 \mathrm{~km}\right)$, the kind of atmospheric waves that should be considered is gravity waves, because the intrinsic phase velocity of smallscale Rossby waves is too slow to distinguish from flows unless strong local beta effects exist, and sound waves are clearly irrelevant. However, in many cases, we do not see clear wave features. The fact that the velocity difference 

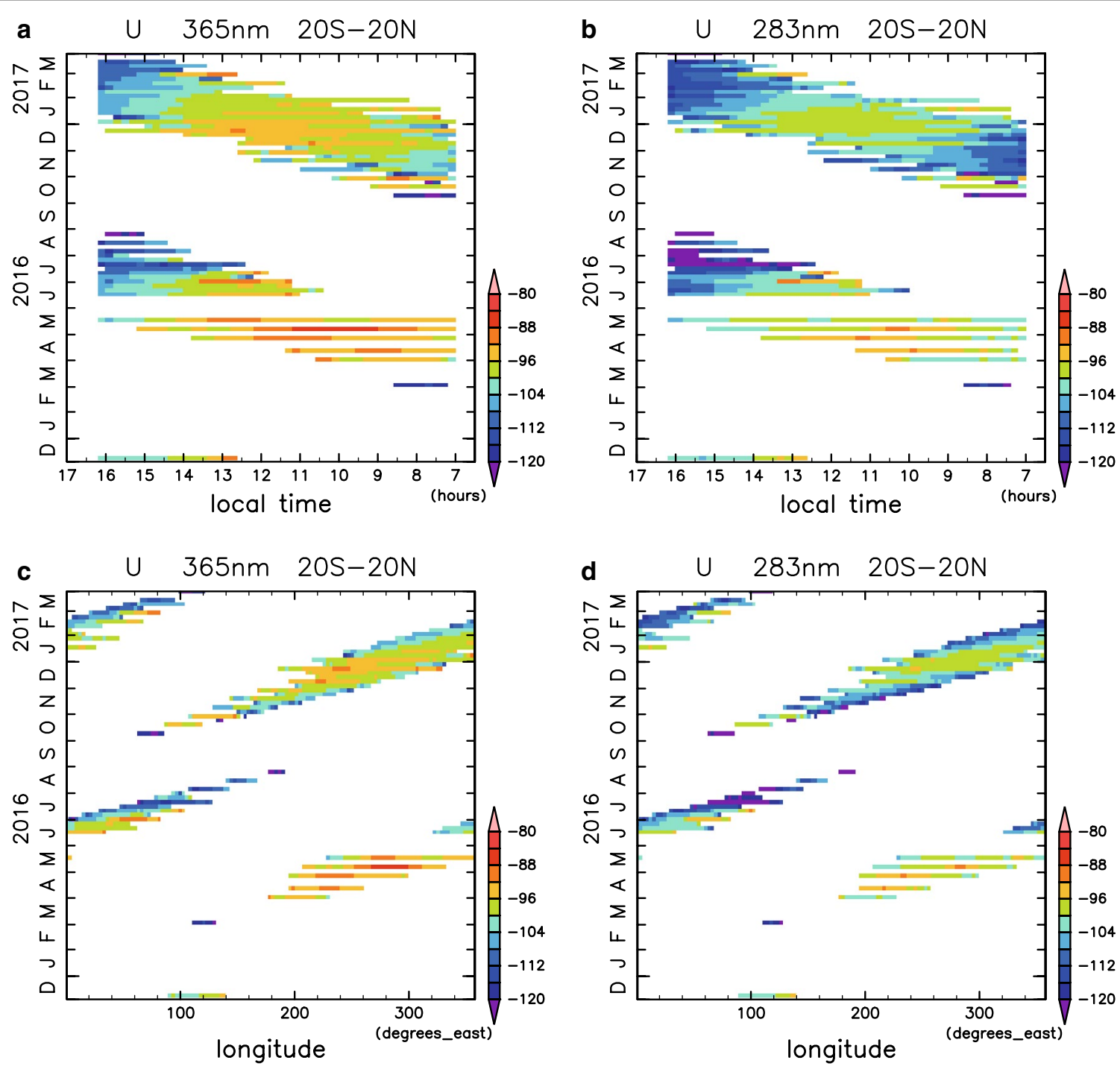

Fig. 8 Mean zonal winds between $20^{\circ} \mathrm{S}$ and $20^{\circ} \mathrm{N}$ averaged over each of 5-day bins in terms of local time $(\mathbf{a}, \mathbf{b})$ and longitude (c, d) from 365 -nm (a c) and 283-nm (c, d) images $(\mathrm{m} / \mathrm{s})$. For a given 5-day bin and local time-longitudinal grid point, the mean value is defined whenever daily averaged wind values are defined on any day in the 5-day period somewhere between the latitudinal range; thus, the representativeness is sometimes quite limited. Local time is defined as in Fig. 7, and the $3^{\circ}$ longitudinal grid is converted into a $0.2-\mathrm{h}$ local time grid in terms of nearest neighbors before computing 5-day means (a, b)

is mainly in the zonal direction indicates that if it is explained by waves, the constant phase lines should be predominantly in the north-south direction. However, such anisotropy is not evident. Therefore, we conclude that the overall difference is likely caused by vertical shear.

Figures 11 and 12 show that the hemispheric asymmetry of mean zonal winds in the latter half of our analysis period is stronger at $365 \mathrm{~nm}$ than at $283 \mathrm{~nm}$ and that the wind difference is greater in the northern hemisphere. This result appears to suggest that the origin of the strong meridional asymmetry in $365-\mathrm{nm}$ winds may partly be in the meridional asymmetry of the altitude where features tracked in the 365-nm images reside. In other words, it may be produced (in part) by a combination of vertical shear and asymmetric altitude sampling. A preliminary 


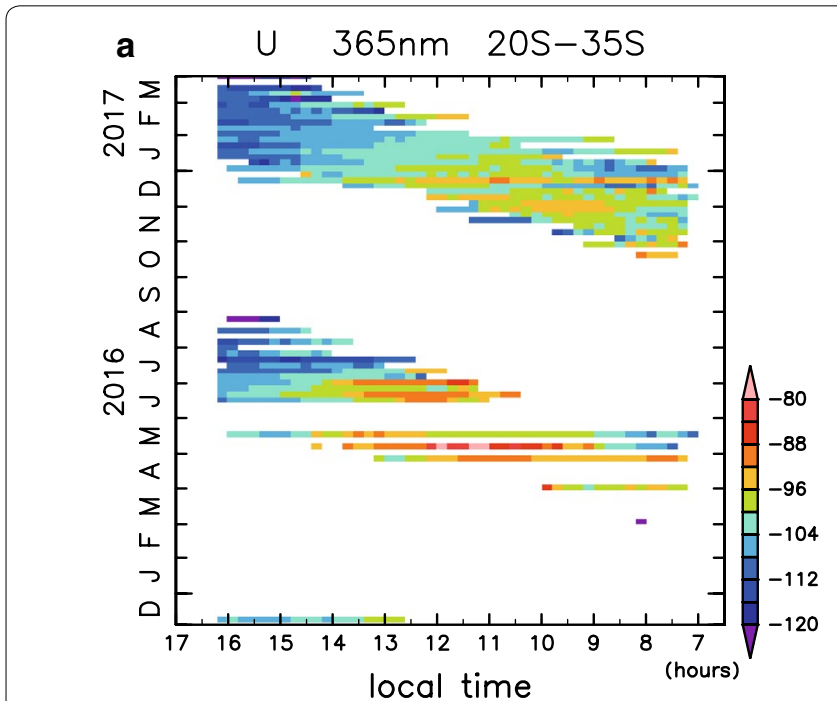

Fig. 9 As in Fig. 8 but for $20-35^{\circ} \mathrm{S}$
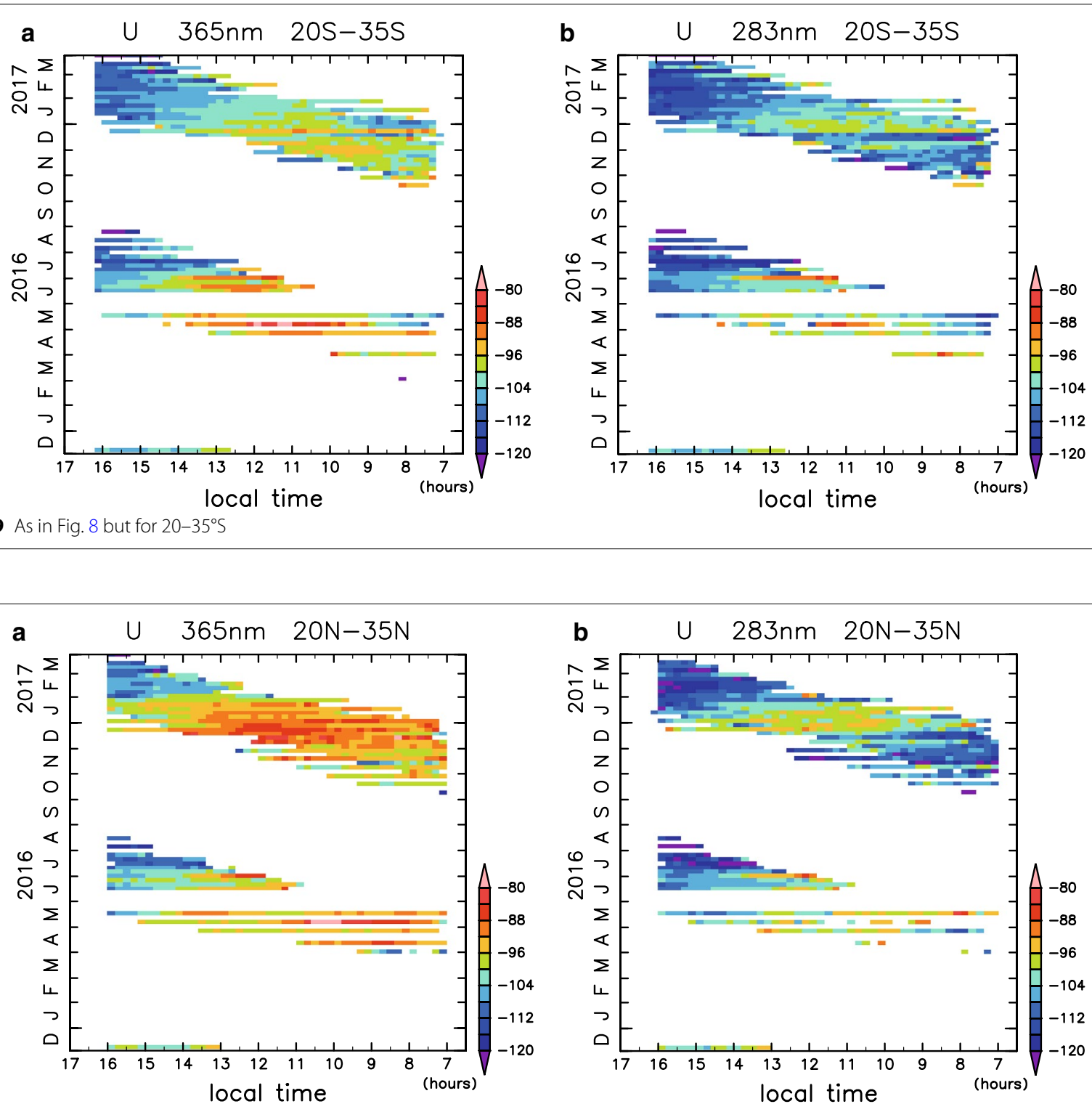

Fig. 10 As in Fig. 8 but for $20-35^{\circ} \mathrm{N}$

analysis of radiance indicates that the albedo at $365 \mathrm{~nm}$ was generally higher in the northern hemisphere than in the southern hemisphere in the latter half of our analysis period, whereas it was more symmetric about the equator in the earlier half.

A question that naturally arises from the above discussion (especially, two paragraphs earlier) is which of the 365- and 283-nm winds represents the flow at higher altitude. Previous studies that derived thermally balanced zonal winds from radio occultation observations suggested that the zonal wind speeds peaked roughly around the altitude of $70 \mathrm{~km}$ where cloud top resides (e.g., Limaye 1985; Piccialli et al. 2012). However, the thermal wind derivation has large uncertainty at low latitude. Studies with entry probe observations have shown the vertical structure of zonal winds at low latitude, but large uncertainty exists above $65 \mathrm{~km}$ (Schubert et al. 1980; Kerzhanovich and Limaye 1985). Therefore, it is difficult to tell whether the faster represent flow at the higher or the lower altitude from these studies. The cloud-tracking studies by using multiple-wavelength images from Galileo and VEx (e.g., Peralta et al. 2007, Sanchez-Lavega 

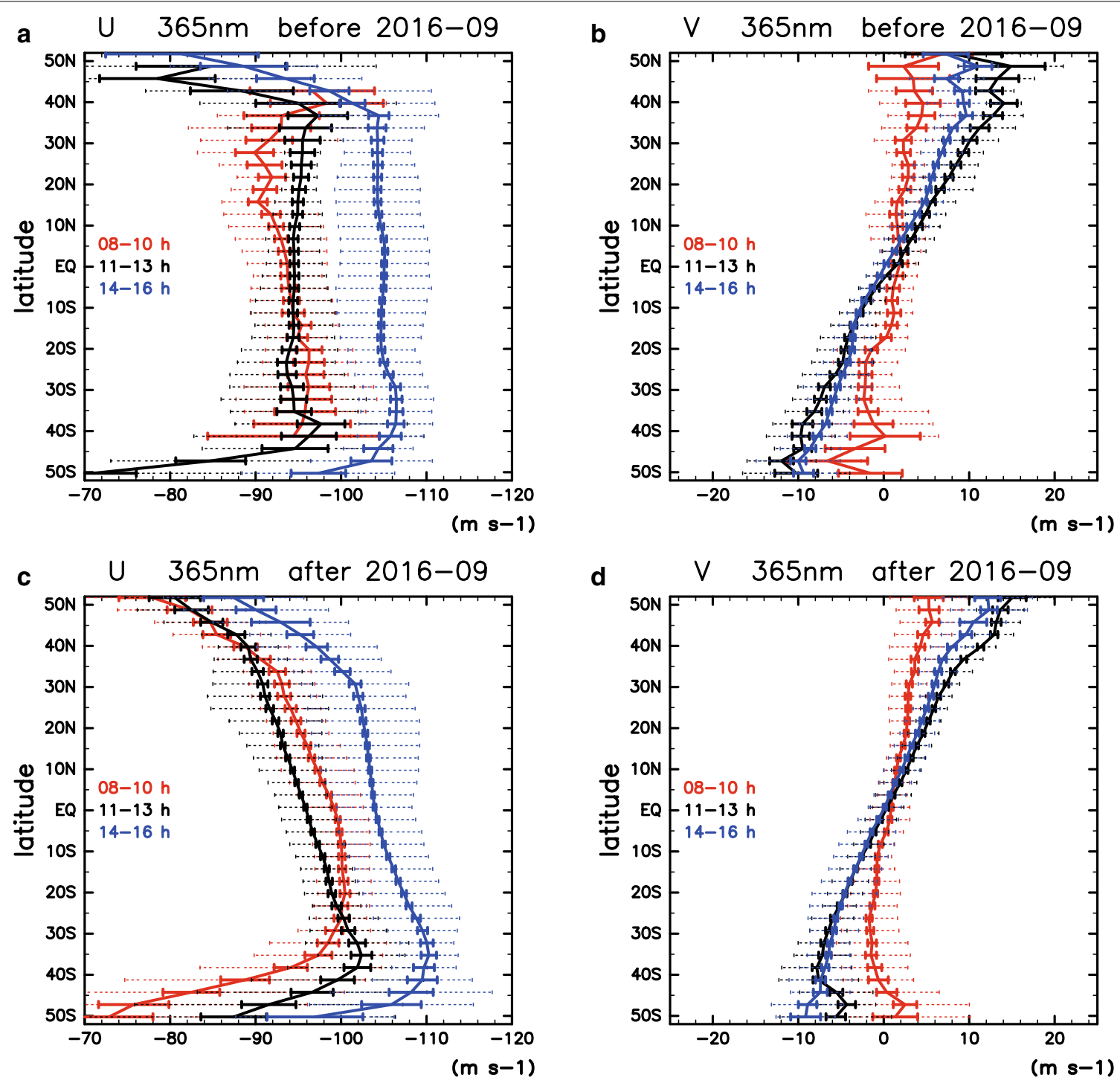

Fig. 11 Meridional profiles of mean winds depending on local time (LT) and observation period. Zonal $(\mathbf{a}, \mathbf{c})$ and meridional (b, $\mathbf{d})$ winds over December 2015-August 2016 (a, b) and October 2016-March 2017 (c, d). The winds are averaged over LTs (derived as in Fig. 7): 8-10 h (red), 11-13 $\mathrm{h}$ (black), and 14-16 h (blue). Thick error bars indicate \pm the precision measures based on $\left\langle\varepsilon_{u}\right\rangle(\mathbf{a}, \mathbf{c})$ and $\left\langle\varepsilon_{v}\right\rangle(\mathbf{b}, \mathbf{d})$; specifically, they represent the RMS of $\left\langle\varepsilon_{u}\right\rangle$ and $\left\langle\varepsilon_{v}\right\rangle$ over each LT range divided by the square root of the effective degrees of freedom defined as the number of LT grid points (at maximum 10 over $2 \mathrm{~h}$ because of the $3^{\circ}$ interval) divided by 3 to account for oversampling. Dotted thin bars show \pm the standard deviation of the 10-day-bin means (within the LT and observation time ranges)

et al. 2008, Hueso et al. 2015) have shown positive (in terms of wind speed) vertical shear below the cloud top, but these studies do not provide information on shear around the cloud top. Also, in a recent work, Peralta et al. (2017) estimated the vertical profile of the zonal winds during the second Venus flyby of NASA's Messenger spacecraft, and the results suggested that on the dayside, the altitude at which the zonal wind peaks seems to vary over time.
A clue to answer the above question is found in the estimated vertical distributions of absorbers. Lee et al. (2017) found that the phase-angle dependency in Akatsuki UVI 365-nm data can be explained if the unknown absorber is distributed slightly below the cloud top rather than above. In contrast, the $\mathrm{SO}_{2}$ mixing ratio increases upward from the cloud-top level (e.g., von Zahn et al. 1983; Belyaev et al. 2012; Mahieux et al. 2015). Therefore, we speculate that the motion obtained from 283-nm 

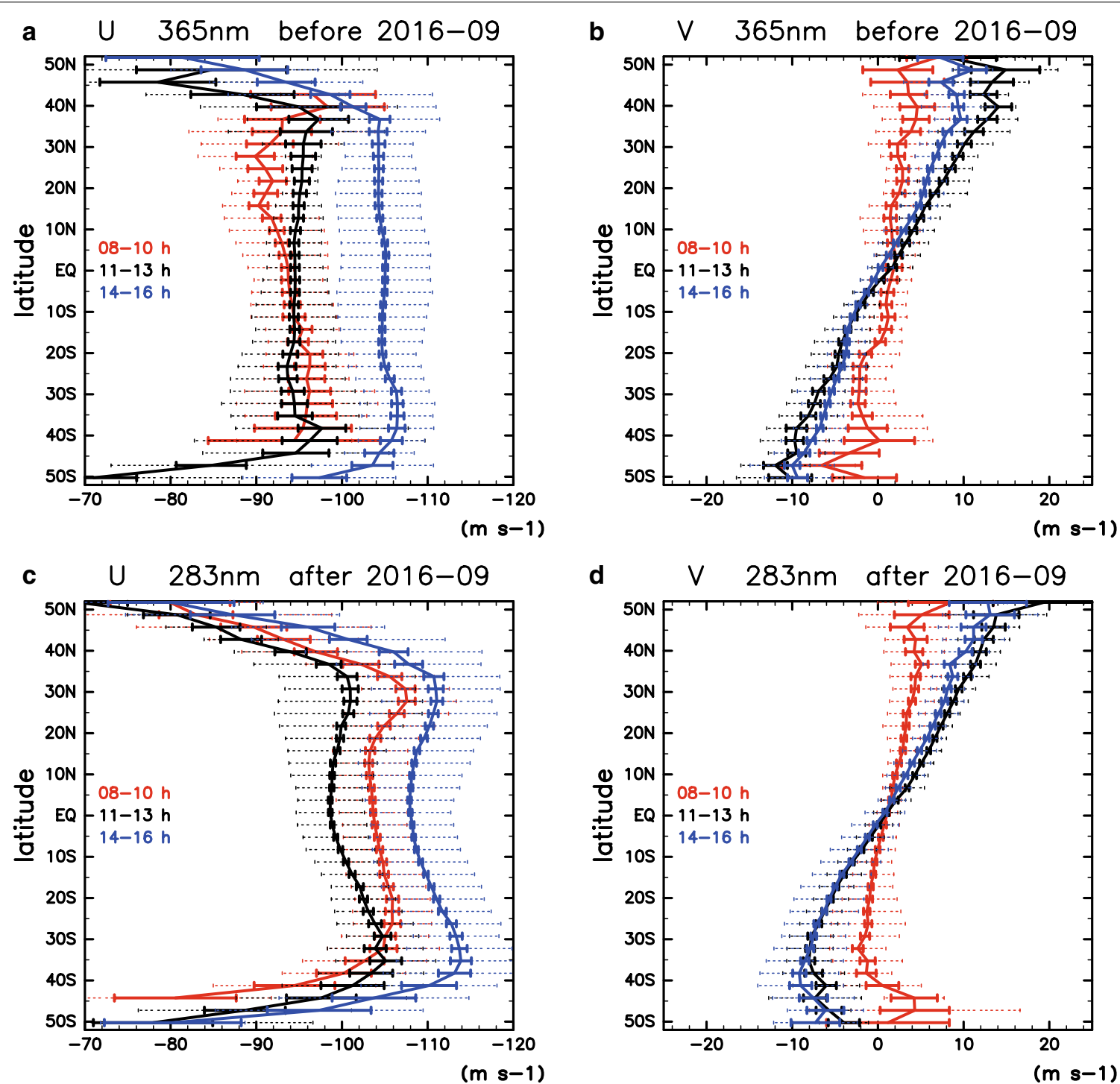

Fig. 12 As in Fig. 11 but for $283 \mathrm{~nm}$

images reflects flows at higher altitude. However, the vertical distribution of $\mathrm{SO}_{2}$ is still poorly constrained (Vandaele et al. 2017), as is the unknown UV absorber. In addition, small-scale features tracked during cloud tracking are not necessarily located at the altitude where the weighting function for each wavelength is maximized. The small-scale features are created through interplays between UV absorbers, clouds, and upper haze, and it is unclear even how they are created. Therefore, our speculation on the relative altitude problem is tentative, and we leave this problem as an open question for future studies.
Another issue to discuss is the discrepancy between our results and those of Bertaux et al. (2016) in terms of geographic distribution of temporal mean zonal winds. Bertaux et al. (2016) used observations over a longer period (7.5 years) than ours (1.3 years). In that sense, their result appears more reliable. However, the longitudinal variation they showed is greater than our result shown in Fig. 8b; therefore, we cannot conclude a priori that the expected sampling error is smaller in their study than in ours. They interpreted their geographic distribution as the result of deceleration caused by topographically 

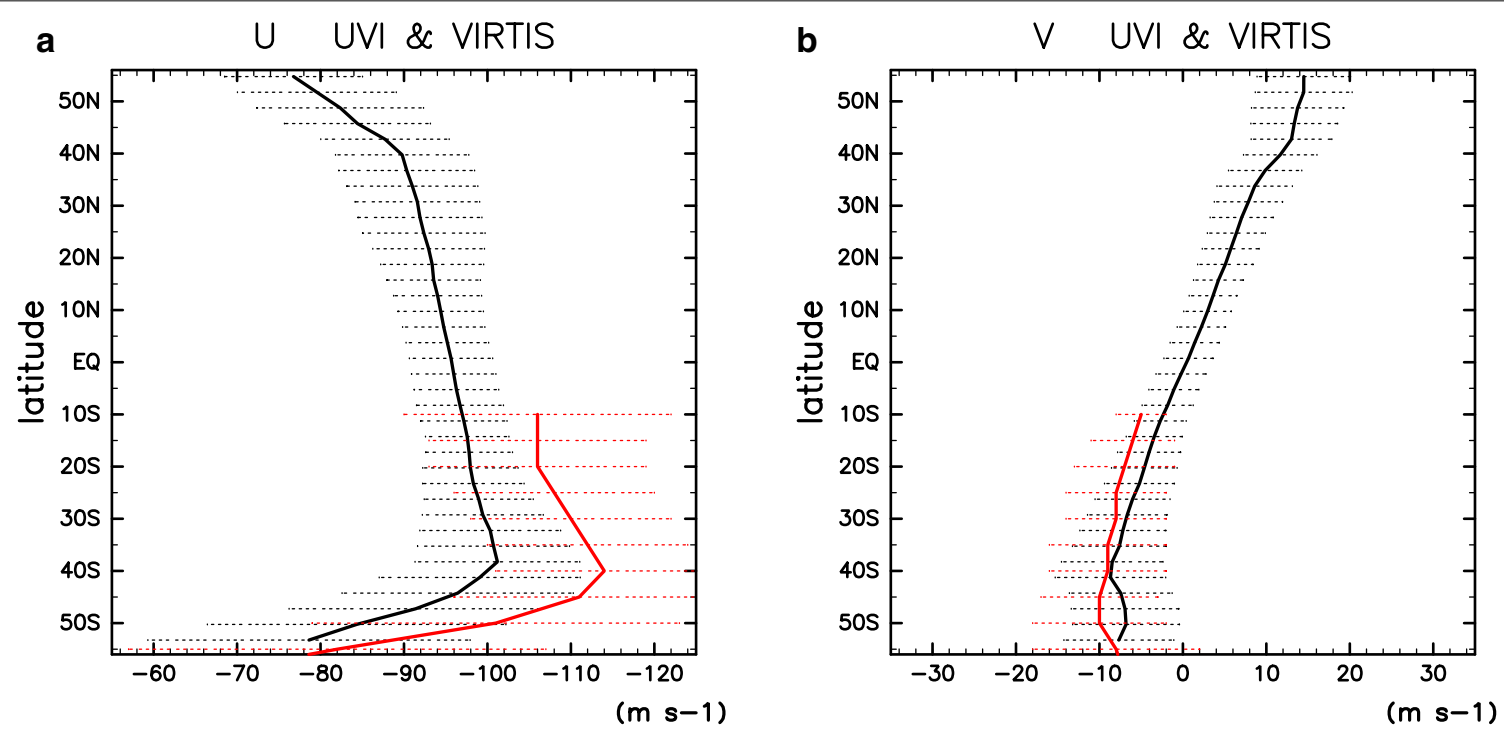

Fig. 13 Comparison of mean winds from 365-nm images by UVI (black, December 2015-March 2017) and VEx/VIRTIS (red, April 2006-February 2012); a zonal and $\mathbf{b}$ meridional winds between the local times 11 and $13 \mathrm{~h}$. Horizontal dotted lines shows \pm the standard deviation for each latitudinal grid point (UVI) or 5-degree latitudinal bin (VIRTIS)

induced gravity waves that propagate from the ground. However, the longitudinal distribution of momentum forcing does not necessarily induce such features, as is evident from the quasi-biennial oscillation $(\mathrm{QBO})$ in the equatorial stratosphere of the Earth. (A review of the QBO is provided by Baldwin et al. 2001.) Even though the driving force of the QBO is known to have significant longitudinal asymmetry, the Earth's equatorial zonal wind has longitudinal variation much smaller than that shown by Bertaux et al. (2016) (Kawatani et al. 2005, 2010). To solve the geographic distribution mystery will require further study.

\section{Summary and conclusions}

We have estimated and investigated winds at the cloud top of Venus using UV images obtained by UVI onboard Akatsuki. The novel automated cloud-tracking method and quality control proposed by $\mathrm{IH} 16$ and H17a enabled us to obtain realistic winds that actually reflect the motion of small-scale features at the wavelengths of 365 and $283 \mathrm{~nm}$, traditional UV imaging based on the unknown UV absorber and the novel UV imaging at an $\mathrm{SO}_{2}$ absorption band, respectively.

Horizontal winds obtained from the 283-nm images are generally similar to those from the $365-\mathrm{nm}$ images, but in many cases, zonal winds obtained from the former are faster than those from the latter, and poleward flows are slightly faster. It was suggested that this difference is associated with vertical wind shear. From the studies of Lee et al. (2017) and others, one can argue that 283-nm images reflect cloud features at higher altitude than 365 $\mathrm{nm}$ images. Therefore, we tentatively conclude that, on average, it is likely that the superrotation of the Venusian atmosphere is increased with height, even at the cloudtop level, where previous studies suggested that the zonal wind speeds are roughly maximized. Further study will be needed to investigate the relative altitude problem.

The VIRTIS-M-VIS images of $\mathrm{SO}_{2}$ absorption bands have not been used a great deal for studies because of a problem in calibration (Shalygina et al. 2015). However, absolute calibration is not necessary for cloud tracking. The present discovery of the mean wind difference suggests that it would be interesting to revisit these data.

We derived mean winds averaged over the observation period as functions of local time and latitude. The results are consistent with previous studies, which have shown the wind structures associated with the thermal tide. Furthermore, the local time-time plots of low-latitude zonal winds suggested a hint of long-term variability, which is consistent with the $\sim 250$-day variability found by Kouyama et al. (2013).

The zonal winds derived in the earlier half of our analysis period are nearly symmetric about the equator, but they are asymmetric in the latter half, especially at $365 \mathrm{~nm}$. This temporal and spatial variability might have occurred at nearly the same altitude for each wavelength 

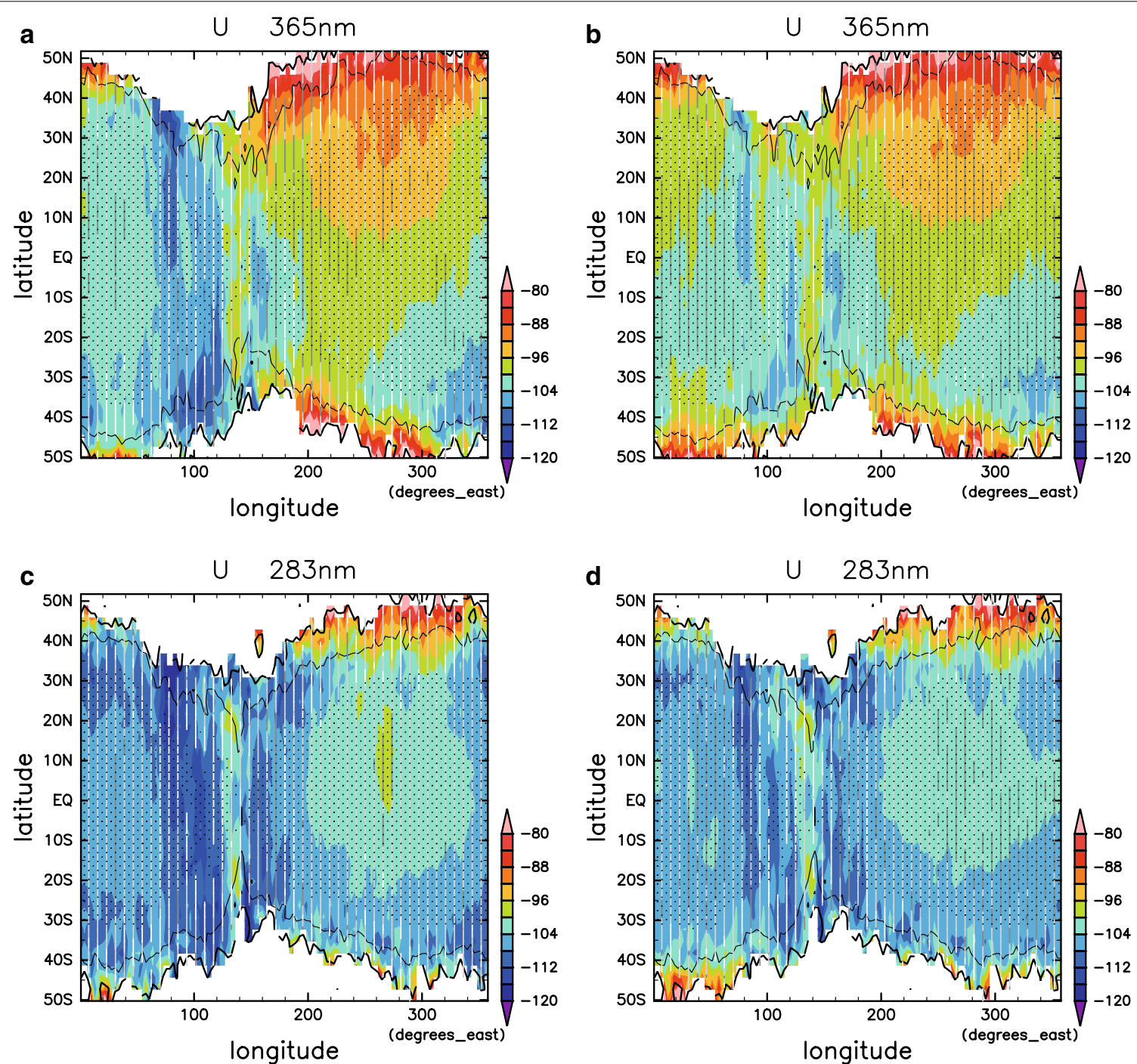

Fig. 14 a As in Fig. 7a but obtained as a function of longitude and latitude. $\mathbf{b}$ As in a except that the local time dependence is subtracted. $\mathbf{c}, \mathbf{d}$ As in a, b but for $283 \mathrm{~nm}$

and latitude, suggesting hemispheric asymmetry of superrotation. However, this result may also be caused by a combination of persistent vertical shear and hemispheric asymmetry of the altitude at which small-scale features captured in the cloud tracking reside.

It should be noted that the long-term variability can be aliased onto the local time-latitude map of mean winds. This problem may be alleviated by using simultaneous ground-based observation from the Earth (SánchezLavega et al. 2016). The tidal structure may also vary slowly with time. Further study is needed to improve our knowledge of the thermal tide in the atmosphere of Venus.

Bertaux et al. (2016) determined the geographic distribution of temporal mean zonal winds using UV images from VEx and suggested that it is a result of forcing by topographically induced stationary gravity waves. However, the geographic distribution we obtained is qualitatively different from theirs. Quantitatively, the geographic variability we obtained is much weaker than that reported by Bertaux et al. (2016). This result indicates that the distribution they showed is not robust or persistent; thus, the topographic impact they proposed may not necessarily occur. Further study would be needed to draw a firm conclusion regarding this issue.

\section{Authors' contributions}

TH conducted cloud tracking using data from Akatsuki, analyzed the derived winds, drew figures, and wrote the paper. YJL interpreted the wavelength dependence. JP conducted cloud tracking with VEXNIRTIS. TK, TI, KN, MT, and $J P$ contributed to the interpretation of the derived winds, thermal tides, and 
mean wind statistics. SM, KO, and TH developed the cloud-tracking program for Akatsuki, and TK advised them. MT, KO, SM, and TK developed the geographic mapping program for Akatsuki's image data. SM conducted Akatsuki image data processing. AY, MY, and SW developed and calibrated UVI. All authors read and approved the final manuscript.

\section{Author details}

${ }^{1}$ Faculty of Environmental Earth Science, Hokkaido University, N10W5, Sapporo, Hokkaido 060-0810, Japan. ${ }^{2}$ Institute of Space and Astronautical Science, Japan Aerospace Exploration Agency, Sagamihara, Japan. ${ }^{3}$ Artificial Intelligence Research Center, National Institute of Advanced Industrial Science and Technology, Tokyo, Japan. ${ }^{4}$ School of Engineering, University of Shiga Prefecture, Hikone, Japan. ${ }^{5}$ Division of Science, Kyoto Sangyo University, Kyoto, Japan. ${ }^{6}$ Present Address: Graduate School of Frontier Sciences, University of Tokyo, Kashiwa, Japan. ${ }^{7}$ Faculty of Sciences, Kyushu University, Fukuoka, Japan. ${ }^{8}$ Planetary Exploration Research Center, Chiba Institute of Technology, Narashino, Japan. ${ }^{9}$ Space Information Center, Hokkaido Information University, Ebetsu, Japan.

\section{Acknowledgements}

We thank Drs. Takehiko Sato, Sanjay Limaye, Masato Nakamura, and Hiroki Kashimura for discussion on UVI tracking results. We thank Dr. Igor Khatuntsev and an anonymous reviewer for providing valuable comments that helped improve the manuscript significantly. We also thank the numerous people who contributed to create and operate the Akatsuki spacecraft. This study was partially supported by JSPS KENHI $16 \mathrm{H} 02231$ and 16H02225 and JAXA's ITYF Fellowship.

\section{Competing interests}

The authors declare that they have no competing interests.

\section{Ethics approval and consent to participate}

Not applicable.

\section{Availability of data and materials}

Radiance data from Akatsuki's cameras are available publicly from the Akatsuki project's data publication site, http://darts.isas.jaxa.jp/planet/project/akatsuki/. The data will also be available from NASA's Planetary Data System (https://pds. nasa.gov/): Atmospheres Node.

\section{Publisher's Note}

Springer Nature remains neutral with regard to jurisdictional claims in published maps and institutional affiliations.

Received: 15 July 2017 Accepted: 25 December 2017

Published online: 15 January 2018

\section{References}

Baldwin MP, Gray LJ, Dunkerton TJ, Hamilton K, Haynes PH, Randel WJ, Holton JR, Alexander MJ, Hirota I, Horinouchi T, Jones DBA, Kinnersley JS, Marquardt C, Sato K, Takahashi M (2001) The quasi-biennial oscillation. Rev Geophys 39:179-229

Belyaev DA, Montmessin F, Bertaux JL, Mahieux A, Fedorova AA, Korablev Ol, Zhang $X$ (2012) Vertical profiling of $\mathrm{SO}_{2}$ and $\mathrm{SO}$ above Venus' clouds by SPICAV/SOIR solar occultations. Icarus 217(2):740-751

Bertaux JL, Khatuntsev IV, Hauchecorne A, Markiewicz WJ, Marcq E, Lebonnois S, Patsaeva M, Turin A, Fedorova A (2016) Influence of Venus topography on the zonal wind and UV albedo at cloud top level: The role of stationary gravity waves. J Geophys Res Planets 121(6):1087-1101

Del Genio AD, Rossow WB (1990) Planetary-scale waves and the cyclic nature of cloud top dynamics on Venus. J Atmos Sci 47(3):293-318

Esposito LW, Bertaux JL, Krasnopolsky V, Moroz VI, Zasova LV (1997) Chemistry of lower atmosphere and clouds. University of Arizona Press, Venus II, pp 415-458

Horinouchi T, Murakami S, Kouyama T, Ogohara K, Yamazaki A, Yamada M, Watanabe S (2017a) Image velocimetry for clouds with relaxation labeling based on deformation consistency. Meas Sci Technol 28(8):085301. https://doi.org/10.1088/1361-6501/aa695c

Horinouchi T et al (2017b) Equatorial jet in the lower to middle cloud layer of Venus revealed by Akatsuki. Nat Geosci 10:646-651. https://doi. org/10.1038/ngeo3016

Hueso R, Peralta J, Garate-Lopez I, Bandos TV, Sánchez-Lavega A (2015) Six years of Venus winds at the upper cloud level from UV, visible and near infrared observations from VIRTIS on Venus Express. Planet Space Sci 113-114:78-99

Ikegawa S, Horinouchi T (2016) Improved automatic estimation of winds at the cloud top of Venus using superposition of cross-correlation surfaces. Icarus 271:98-119

Kawatani Y, Tsuji K, Takahashi M (2005). Zonally non-uniform distribution of equatorial gravity waves in an atmospheric general circulation model. Geophys Res Lett 32:L23815. https://doi.org/10.1029/2005GL024068

Kawatani Y, Watanabe S, Sato K, Dunkerton TJ, Miyahara S, Takahashi M (2010) The roles of equatorial trapped waves and internal inertia-gravity waves in driving the quasi-biennial oscillation. Part II: three-dimensional distribution of wave forcing. J Atmos Sci 67(4):981-997

Kerzhanovich WV, Limaye SS (1985) Circulation of the atmosphere from the surface to $100 \mathrm{~km}$. Adv Space Res 5(11):59-83

Khatuntsev IV, Patsaeva MV, Titov DV, Ignatiev NI, Turin AV, Limaye SS, Markiewicz WJ, Almeida M, Roatsch T, Moissl R (2013) Cloud level winds from the Venus Express Monitoring Camera imaging. Icarus 226(1):140-158

Kouyama T, Imamura T, Nakamura M, Satoh T, Futaana Y (2012) Horizontal structure of planetary-scale waves at the cloud top of Venus deduced from Galileo SSI images with an improved cloud-tracking technique. Planet Space Sci 60(1):207-216

Kouyama T, Imamura T, Nakamura M, Satoh T, Futaana Y (2013) Long-term variation in the cloud-tracked zonal velocities at the cloud top of Venus deduced from Venus Express VMC images. J Geophys Res (Planets) 118(1):37-46

Lee YJ, Titov DV, Tellmann S, Piccialli A, Ignatiev N, Patzold M, Hausler B, Piccioni G, Drossart P (2012) Vertical structure of the Venus cloud top from the VeRa and VIRTIS observations onboard Venus Express. Icarus 217(2):599-609

Lee YJ, Yamazaki A, Imamura T, Yamada M, Watanabe S, Sato TM, Ogohara K, Hashimoto GL, Murakami S (2017) Scattering properties of the Venusian clouds observed by UV Imager on board Akatsuki. Astron J 154:44. https://doi.org/10.3847/1538-3881/aa78a5

Limaye SS (1984) Morphology and movements of polarization features on Venus as seen in the Pioneer Orbiter Cloud Photopolarimeter data. Icarus 57:362-385

Limaye SS (1985) Venus atmospheric circulation: observations and implications of the thermal structure. Adv Space Res 5(9):51-62

Limaye SS (1988) Venus: cloud level circulation during 1982 as determined from Pioneer Cloud Polarimeter images. II. Solar longitude dependent circulation. Icarus 73:212-226

Limaye SS, Suomi VE (1981) Cloud motions on Venus: global structure and organization. J Atmos Sci 38(6):1220-1235

Limaye SS, Grund CJ, Burre SP (1982) Zonal mean circulation at the cloud level on Venus: spring and Fall 1979 OCPP observations. Icarus 51(2):416-439

Limaye SS, Grassott C, Kuetemeyer MJ (1988) Venus: cloud level circulation during 1982 as determined from Pioneer Cloud Photopolarimeter images. I. Time and zonally averaged circulation. Icarus 73:193-211

Luginin M, Fedorova A, Belyaev D, Montmessin F, Wilquet V, Korablev O, Bertaux J-L, Vandaele AC (2016) Aerosol properties in the upper haze of Venus from SPICAV IR data. Icarus 277:154-170

Mahieux A, Vandaele AC, Robert S, Wilquet V, Drummond R, Chamberlain S, Belyaev D, Bertaux JL (2015) Venus mesospheric sulfur dioxide measurement retrieved from SOIR on board Venus Express. Planet Space Sci 113:193-204

Markiewicz WJ, Petrova E, Shalygina O, Almeida M, Titov DV, Limaye SS, Ignatiev N, Roatsch T, Matz KD (2014) Glory on Venus cloud tops and the unknown UV absorber. Icarus 234:200-203

Moissl R et al (2009) Venus cloud top winds from tracking UV features in Venus Monitoring Camera images. J Geophys Res (Planets) 114:EO0B31. https:// doi.org/10.1029/2008je003117

Molaverdikhani K, McGouldrick K, Esposito LW (2012) The abundance and vertical distribution of the unknown ultraviolet absorber in the Venusian 
atmosphere from analysis of Venus Monitoring Camera images. Icarus 217:648-660

Nakamura M et al (2016) AKATSUKI returns to Venus. Earth Planets Space 68:75. https://doi.org/10.1186/s40623-016-0457-6

Ogohara K et al (2012) Automated cloud tracking system for the Akatsuki Venus Climate Orbiter data. Icarus 217:661-668. https://doi.org/10.1016/j. icarus.2011.05.017

Ogohara K et al (2017) Overview of Akatsuki data products: the first quality and accuracy estimations. Earth Planets Space 69:167. https://doi. org/10.1186/s40623-017-0749-5

Patsaeva MV, Khatuntsev IV, Patsaev DV, Titov DV, Ignatiev NI, Markiewicz WJ, Rodin AV (2015) The relationship between mesoscale circulation and cloud morphology at the upper cloud level of Venus from VMCNenus Express. Planet Space Sci 113:100-108

Peralta J, Huseo R, Sanchez-Lavega A (2007) A reanalysis of Venus winds at two cloud levels from Galileo SSI images. Icarus 190:469-477

Peralta J, Lee YJ, Hueso R, Clancy R, Sandor B, Sánchez-Lavega A, Lellouch E, Rengel M, Machado P, Omino M, Piccialli A, Imamura T, Horinouchi T, Murakami S, Ogohara K, Luz D, Peach D (2017) Venus's Winds and Temperatures during the Messenger's flyby: an approximation to a threedimensional instantaneous state of the atmosphere. Geophys Res Lett 44:3907-3915

Piccialli A, Tellmann S, Titov DV, Limaye SS, Khatuntsev IV, Pätzold M, Häusler B (2012) Dynamical properties of the Venus mesosphere from the radio-occultation experiment VeRa onboard Venus Express. Icarus 217(2):669-681

Pollack JB, Toon OB, Whitten RC, Boese R, Ragent B, Tomasko M, Esposite L, Travis L, Wiedman D (1980) Distribution and source of the UV absorption in Venus' atmosphere. J Geophys Res 85(A13):8141-8150

Rossow WB, Del Genio AD, Limaye SS, Travis LD, Stone PH (1980) Cloud morphology and motions from Pioneer Venus images. J Geophys Res 85(A13):8107-8128

Rossow WB, del Genio AD, Eichler T (1990) Cloud-tracked winds from Pioneer Venus OCPP images. J Atmos Sci 47(17):2053-2084
Sánchez-Lavega A et al (2008) Variable winds on Venus mapped in three dimensions. Geophys Res Lett. https://doi.org/10.1029/2008GL033817

Sánchez-Lavega A et al (2016) Venus cloud morphology and motions from ground-based images at the time of the Akatsuki orbit insertion. Astrophys J Lett 833:L7

Schubert G et al (1980) Structure and circulation of the Venus atmosphere. J Geophys Res 85(A13):8007-8025

Shalygina OS, Petrova EV, Markiewicz WJ, Ignatiev NI, Shalygin EV (2015) Optical properties of the Venus upper clouds from the data obtained by Venus Monitoring Camera on-board the Venus Express. Planet Space Sci 113:135-158

Titov DV et al (2012) Morphology of the cloud tops as observed by the Venus Express Monitoring Camera. Icarus 217:682-701

Toigo A, Gierasch PJ, Smit MD (1994) High resolution cloud feature tracking on Venus by Galileo. Icarus 109:318-336

Vandaele AC et al (2017) Sulfur dioxide in the Venus atmosphere: I. Vertical distribution and variability. Icarus 295:16-33

von Zahn U, Kumar S, Niemann H, Prinn R (1983) Composition of the Venus atmosphere, vol 13. Venus. University of Arizona Press, Tucson, pp 299-430

Wilquet V, Fedorova A, Montmessin F, Drummond R, Mahieux A, Vandaele AC, Villard E, Korablev O, Bertaux J-L (2009) Preliminary characterization of the upper haze by SPICAV/SOIR solar occultation in UV to mid-IR onboard Venus Express. J Geophys Res 114:E00B42. https://doi. org/10.1029/2008je003186

Wilquet V, Drummond R, Mahieux A, Robert S, Vandaele AC, Bertaux JL (2012) Optical extinction due to aerosols in the upper haze of Venus: four years of SOIRNEX observations from 2006 to 2010. Icarus 217(2):875-881

Yamazaki A et al (2017) Ultraviolet imager on venus climate orbiter, Akatsuki and its initial results. Earth Planets Space. https://doi.org/10.1186/ s40623-017-0772-6

\section{Submit your manuscript to a SpringerOpen ${ }^{\odot}$ journal and benefit from:}

- Convenient online submission

- Rigorous peer review

- Open access: articles freely available online

- High visibility within the field

- Retaining the copyright to your article

Submit your next manuscript at $\boldsymbol{\nabla}$ springeropen.com 